\title{
SITUATION OF HANTAVIRUS INFECTIONS AND HAEMORRHAGIC FEVER WITH RENAL SYNDROME IN EUROPEAN COUNTRIES AS OF DECEMBER 2006
}

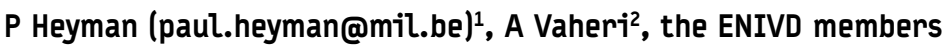

1. Research Laboratory for Vector-Borne Diseases, National Reference Centre for Hantavirus Infections, Queen Astrid Military Hospital, Brussels, Belgium

2. Department of Virology, Haartman Institute, University of Helsinki, Helsinki, Finland

\begin{abstract}
Hantavirus infections are widely distributed in Europe with the exception of the far north and the Mediterranean regions. The underlying causes of varying epidemiological patterns differ among regions: in western and central Europe epidemics of haemorrhagic fever with renal syndrome (HFRS) caused by hantavirus infections follow mast years with increased seed production by oak and beech trees followed by increased rodent reproduction. In the northern regions, hantavirus infections and HFRS epidemics occur in three to four year cycles and are thought to be driven by prey - predator interactions. Hantavirus infections and HFRS seem to be on the increase in Europe, partly because of better diagnostics, partly perhaps due to environmental changes. Unfortunately, hantavirus infections are still heavily under-diagnosed in many European countries. Here we report the results of a survey conducted in 2007 amongst the member laboratories of the European Network for diagnostics of Imported Viral Diseases (ENIVD).
\end{abstract}

\section{Introduction}

Hantaviruses (family Bunyaviridae, genus Hantavirus) are enveloped RNA viruses, carried primarily by rodents or insectivores of specific host species [1]. Three hantaviruses, Puumala (PUUV), Dobrava (DOBV) and Saaremaa (SAAV), are known to cause haemorrhagic fever with renal syndrome (HFRS) in Europe. Puumala virus, carried by the bank vole (Myodes glareolus, previously known as Clethrionomys glareolus) and Saaremaa virus, carried by the striped field mouse (Apodemus agrarius), are associated with mild HFRS. Saaremaa virus (also known as Dobrava Aa., Aa. standing for $A$. agrarius) has been found in Denmark, Estonia, southeast Finland, Germany, Russia, Slovakia and Slovenia. There are no well-documented SAAV-HFRS cases [2]. Dobrava virus (also known as Dobrava Af., Af. standing for Apodemus flavicollis), carried by the yellow-necked mouse ( $A$. flavicollis) has been found in Albania, Bosnia-Herzegovina, Czech Republic, Croatia, Greece, Hungary, Russia, Serbia and Slovenia and causes severe HFRS [2]. In addition, the European common vole (Microtus arvalis) carries Tula virus (TULV), and rats (Rattus norvegicus, $R$. rattus) are carriers of Seoul virus (SEOV) [3]. However, these two viruses have not been definitely associated with disease in Europe [3], although both can infect humans as indicated by reports from Asia (China, South Korea) [4] and the United States where the virus has been associated with chronic kidney diseases [5]. In several European Union (EU) countries hantavirus infections are notifiable and in some countries (e.g. Belgium, France, Germany, the Scandinavian countries, Slovenia) their epidemiology was relatively well studied. In large areas of Europe, however, hantavirus infections and HFRS have not been studied systematically. In many countries the number of infections has been on the increase in recent years (Table 2). The European Network for diagnostics of Imported Viral Diseases (ENIVD, http://www.enivd.de) has conducted a survey of hantavirus infections and HFRS in order to learn more about the epidemiological features and public health impact and discuss factors that influence the occurrence of the disease.

Material and Methods

To obtain a more detailed overview of hantavirus infections in the EU, Bosnia-Herzegovina, Norway, Russia and Switzerland, a questionnaire was sent to all 30 members of the ENIVD. The following data were collected in 2007:

- Year in which laboratories implemented the diagnostic for hantaviruses;

- Methods used for screening and confirmation e.g. EnzymeLinked Immuno Sorbent Assay (ELISA), Indirect Fluorescence Assay (IFA), Focus Reduction Neutralisation Tests (FRNT), Western Blot (WB) and RT-PCR.

- Notification status of hantavirus disease;

- Annual number of human cases;

- Years with increased hantavirus infections in humans

- Local rodent species (whether the species is known as hantavirus carrier or not)

- Circulating hantavirus serotypes in rodents

- Hantavirus serotypes known to cause human disease locally;

- Geographic distribution of the human cases in the country.

For the analysis of trends and identification of epidemic years, Belgium and France were chosen as examples (Figure 1) for western Europe, Finland, Norway and Sweden (Fennoscandia) represented northern Europe (Figure 2) and Austria, Bosnia-Herzegovina, Hungary and Slovenia, (Figure 3) represent central Europe. Our study covered the period from the start of hantavirus diagnostics in a given country until the end of the year 2006. Laboratories from 23 countries (19 EU Member States and four collaborating countries, i.e. Bosnia-Herzegovina, Norway, Russia and Switzerland) completed the questionnaire. No data were obtained from seven of 30 countries, i.e. Bulgaria, Estonia, Ireland, Latvia, Malta, Poland, Slovakia and the United Kingdom. 
T A B L E 1

Hantavirus cases by country in the European Union, Bosnia-Herzegovina, Norway, Russia and Switzerland, ENIVD study 2007

\begin{tabular}{|c|c|c|c|c|c|}
\hline Country* & $\begin{array}{l}\text { Year when diagnostic } \\
\text { was started }\end{array}$ & $\begin{array}{l}\text { Number of cases } \\
\text { reported per year } \\
\text { by the reference } \\
\text { laboratory }\end{array}$ & $\begin{array}{l}\text { Percentage of total } \\
\text { cases reported in the } \\
\text { European Union }\end{array}$ & Notifiable disease** & Hantavirus Serotype \\
\hline Austria & Not available & 198 & 0.60 & No & PUUV \\
\hline Belgium & 1981 & 1856 & 5.66 & Yes & PUUV \\
\hline Cyprus & 2005 & 0 & 0.00 & No & \\
\hline Czech Republic & 1998 & 23 & 0.07 & Yes & PUUV \\
\hline Denmark & 1999 & 0 & 0.00 & Yes & PUUV \\
\hline Finland & 1979 & 24,672 & 72.22 & Yes & PUUV \\
\hline France & 1987 & 1,536 & 4.68 & No & PUUV \\
\hline Germany & 2001 & 1,320 & 4.03 & Yes & PUUV/DOBV/SAAV \\
\hline Greece & 1997 & 37 & 0.11 & Yes & DOBV \\
\hline Hungary & 1992 & 302 & 0.92 & Yes & PUUV/DOBV/SAAV \\
\hline Italy & 1991 & 0 & 0.00 & Yes & None \\
\hline Lithuania & 2000 & 9 & 0.03 & Yes & PUUVISAAV \\
\hline Luxembourg & 2000 & 16 & 0.05 & Yes & PUUV \\
\hline Netherlands & 1994 & 43 & 0.13 & Yes & PUUV \\
\hline Portugal & 1990 & 31 & 0.09 & No & ? \\
\hline Romania & 2005 & 2 & 0.01 & No & PUUV/DOBV \\
\hline Slovenia & 1985 & 221 & 0.67 & Yes & PUUV/DOBV \\
\hline Spain & 2001 & 0 & 0.00 & No & None \\
\hline Sweden & 1994 & 3,516 & 10.73 & Yes & PUUV \\
\hline Bosnia-Herzegovina & 1990 & 555 & 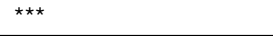 & Yes & PUUV/DOBV \\
\hline Norway & 1990 & 1,084 & 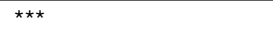 & Yes & PUUV \\
\hline Russia & 1980 & $\begin{array}{l}89,162 \\
(1996-2006)\end{array}$ & 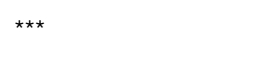 & Yes & $\begin{array}{l}\text { PUUV/DOBV/TULVI } \\
\text { HTNV/AMRV/SAAVV }\end{array}$ \\
\hline Switzerland & 2000 & 1 & 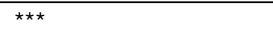 & Yes & TULV \\
\hline
\end{tabular}

* no information obtained for Bulgaria, Estonia, Ireland, Latvia, Malta, Poland, Slovakia, United Kingdom

$\star \star$ hantavirus infection is a -by law- notifiable disease, within 48 hrs after confirmation in the laboratory

$\star \star \star$ non-EU Member State.

\section{T A B L E 2}

Hantavirus cases in 19 EU Member States and Bosnia-Herzegovina, Norway, Russia and Switzerland, ENIVD study 2007

\begin{tabular}{|c|c|c|c|c|c|c|c|c|c|c|c|c|c|c|c|c|c|c|c|c|c|c|c|}
\hline & AT & BE & CY & CZ & DK & FI & FR & DE & EL & HU & IT & LT & LU & $\mathrm{NL}$ & PT & RO & SI & ES & SE & BIH & NO & RU & SW \\
\hline 1979 & & 0 & & & & 31 & & & & & & & & & & & & & & & & & \\
\hline 1980 & & 0 & & & & 9 & & & & & & & & & & & & & & & & & \\
\hline 1981 & & 39 & & & & 19 & & & & & & & & & & & & & & & & & \\
\hline 1982 & & 4 & & & & 64 & & & & & & & & & & & & & & & & & \\
\hline 1983 & & 3 & & & & 80 & & & & & & & & & & & & & & & & & \\
\hline 1984 & & 3 & & & & 108 & & & & & & & & & & & & & & & & & \\
\hline 1985 & & 3 & & & & 124 & & & & & & & & & & & 4 & & & & & & \\
\hline 1986 & & 4 & & & & 132 & & & & & & & & & & & 2 & & & & & & \\
\hline 1987 & & 14 & & & & 117 & 13 & & & & & & & & & & 13 & & & & & & \\
\hline 1988 & & 0 & & & & 302 & 25 & & & & & & & & & & 6 & & & & & & \\
\hline 1989 & & 1 & & & & 686 & 20 & & & & & & & & & & 11 & & & & & & \\
\hline 1990 & & 62 & & & & 839 & 87 & & & & & & & & 0 & & 12 & & & 18 & 46 & & \\
\hline 1991 & & 40 & & & & 966 & 61 & & & & & & & & 0 & & 3 & & & & 74 & & \\
\hline 1992 & & 18 & & & & 1,081 & 36 & & & 12 & & & & & 0 & & 19 & & & & 37 & & \\
\hline 1993 & 2 & 174 & & & & 942 & 165 & & & 19 & & & & & 1 & & 11 & & & & 33 & & \\
\hline 1994 & 2 & 32 & & & & 1,071 & 25 & & & 20 & & & & 0 & 1 & & 7 & & 116 & & 66 & & \\
\hline 1995 & 5 & 22 & & & & 1,012 & 40 & & & 18 & & & & 2 & 1 & & 14 & & 246 & 354 & 80 & & \\
\hline 1996 & 16 & 224 & & & & 907 & 211 & & & 2 & & & & 7 & 6 & & 5 & & 177 & & 32 & & \\
\hline 1997 & 7 & 52 & & & & 758 & 38 & & 4 & 4 & & & & 6 & 3 & & 2 & & 145 & & 81 & & \\
\hline 1998 & 10 & 55 & & 1 & & 1,306 & 37 & & 5 & 17 & & & & 0 & 2 & & 2 & & 562 & & 230 & & \\
\hline 1999 & 10 & 159 & & 0 & & 2,300 & 118 & & 3 & 60 & & & & 6 & 3 & & 5 & & 432 & & 91 & 10,223 & \\
\hline 2000 & 12 & 91 & & 0 & & 774 & 65 & & 1 & 78 & & & 1 & 3 & 2 & & 16 & & 145 & & 37 & 7,403 & 1 \\
\hline 2001 & 13 & 129 & & 0 & & 1,057 & 78 & 185 & 3 & 19 & & & 2 & 5 & 2 & & 6 & & 360 & & 61 & 8,356 & 0 \\
\hline 2002 & 14 & 48 & & 9 & & 2,603 & 60 & 228 & 8 & 29 & & & 0 & 2 & 2 & & 33 & & 262 & 136 & 38 & 4,605 & 0 \\
\hline 2003 & 7 & 122 & & 4 & & 1,566 & 129 & 144 & 2 & 11 & & & 1 & 3 & 2 & & 6 & & 179 & & 39 & 6,161 & 0 \\
\hline 2004 & 72 & 25 & & 4 & & 1,429 & 55 & 242 & 4 & 7 & & 9 & 1 & 3 & 1 & & 15 & & 459 & & 48 & 10,244 & 0 \\
\hline 2005 & 16 & 372 & & 3 & & 2,526 & 253 & 448 & 5 & 6 & & & 8 & 3 & 1 & 1 & 24 & & 330 & 21 & 65 & 7,348 & 0 \\
\hline 2006 & 12 & 163 & & 2 & & 1,863 & 20 & 73 & 4 & & & & 3 & 3 & 4 & 1 & 5 & & 103 & 26 & 26 & 7,210 & 0 \\
\hline Total & 198 & 1859 & 0 & 23 & 0 & 24,672 & 1,536 & 1,320 & 39 & 302 & 0 & 9 & 16 & 43 & 31 & 2 & 221 & 0 & 3,516 & 555 & 1,084 & 61,550 & 1 \\
\hline
\end{tabular}

AT: Austria, BE: Belgium, CY: Cyprus, CZ: Czech Republic, DK: Denmark, F: Finland, FR: France, DE: Germany, EL: Greece, HU: Hungary, IT: Italy, LT: Lithuania, LU:

Luxembourg, NL: Netherlands, PT: Portugal, RO: Romania, SI: Slovenia, ES: Spain, SE: Sweden, BIH: Bosnia and Herzegovina, NO: Norway, RU: Russia, SW: Switzerland. 
F I G U R E 1

Trends of hantavirus infections in Belgium and France, 1990-2006, ENIVD study 2007

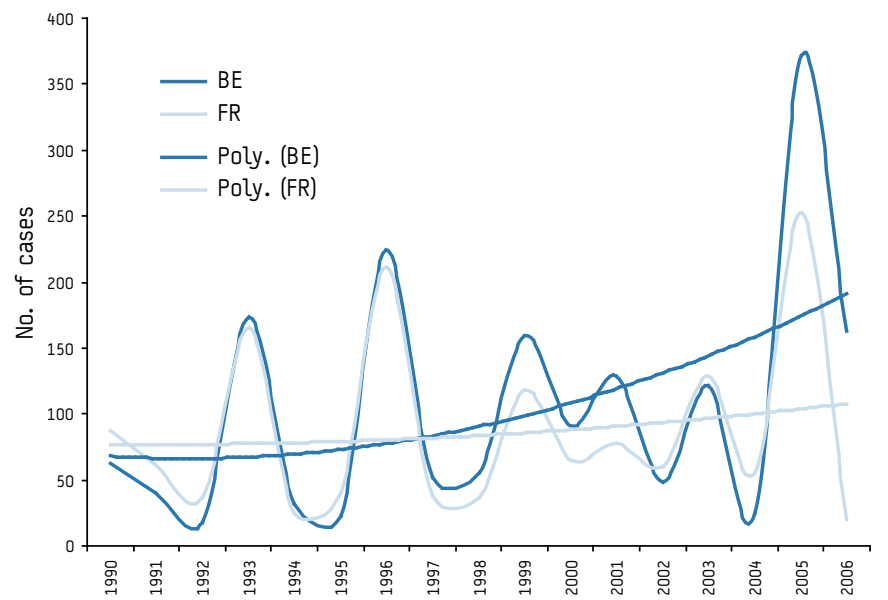

Dark blue: yearly number of cases in Belgium Light blue: yearly number of cases in France

Poly : Polynomial trendline: Calculates the least squares fit through points by using the following equation:

$y=b+c 1 x+c 2 \times 2+c 3 \times 3+\ldots . .16 \times 6$, where $b$ and $c 1 \ldots . .6$ are constants.

Trendlines in corresponding colour.

\section{F I G U R E 2}

Trends of hantavirus infections in Finland, Norway and Sweden, 1990-2006, ENIVD study 2007

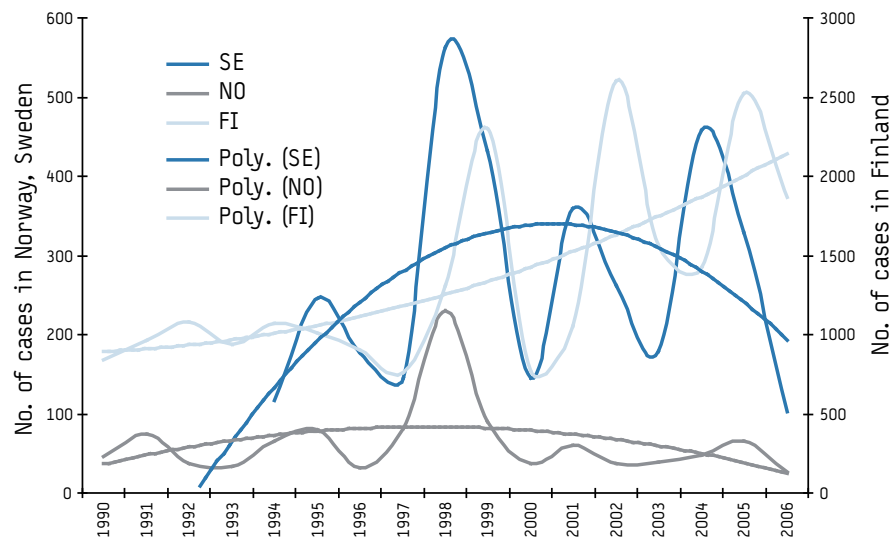

Dark blue: yearly number of cases in Sweden

Light blue: yearly number of cases in Finland

Grey: yearly number of cases in Norway

Poly : Polynomial trendline: Calculates the least squares fit through points by using the following equation:

$y=b+c 1 x+c 2 \times 2+c 3 \times 3+\ldots . . c 6 \times 6$, where $b$ and $c 1 . . . c 6$ are constants.

Trendlines in corresponding colour.

\section{Results}

Start of hantavirus diagnostics

Laboratory diagnostic of hantavirus infections had been initiated before 1990 in six of the responding 23 countries: Finland (1979), Russia (1980), Belgium (1981), Sweden (1984), Slovenia (1985) and France (1987). The remaining 17 countries started diagnostic testing after 1990.

\section{Methods used for screening and confirmation}

Commercial and/or in-house ELISA and IFA were used for screening. If a blood sample was available in the first four days after onset of symptoms, RT-PCR was an option in some cases. FRNT can be applied to recover the causal serotype from convalescent sera.

\section{Notification status}

A notifiable disease is a disease which by law has to be reported to the appropriate authorities within a time frame defined by the national authorities, usually within 48 hours after laboratory diagnosis. Hantavirus infections are notifiable in 17 of the 23 reporting countries; they are not notifiable in Austria, Cyprus, France, Portugal, Romania and Spain (see Table 1).

\section{Number of cases}

Our survey accounted for a total of 35,424 laboratory confirmed cases, 33,587 (94.8\%) of which were detected between 1990 and 2006 . Finland reported 24,672 cases, accounting for $69.6 \%$ of all European cases. No hantavirus cases were reported from Cyprus, Denmark, Italy and Spain. In Russia, the European part accounted

\section{F I G U R E 3}

Trends of hantavirus infections in Austria, Bosnia-Herzegovina, Hungary and Slovenia, 1990-2006, ENIVD study 2007

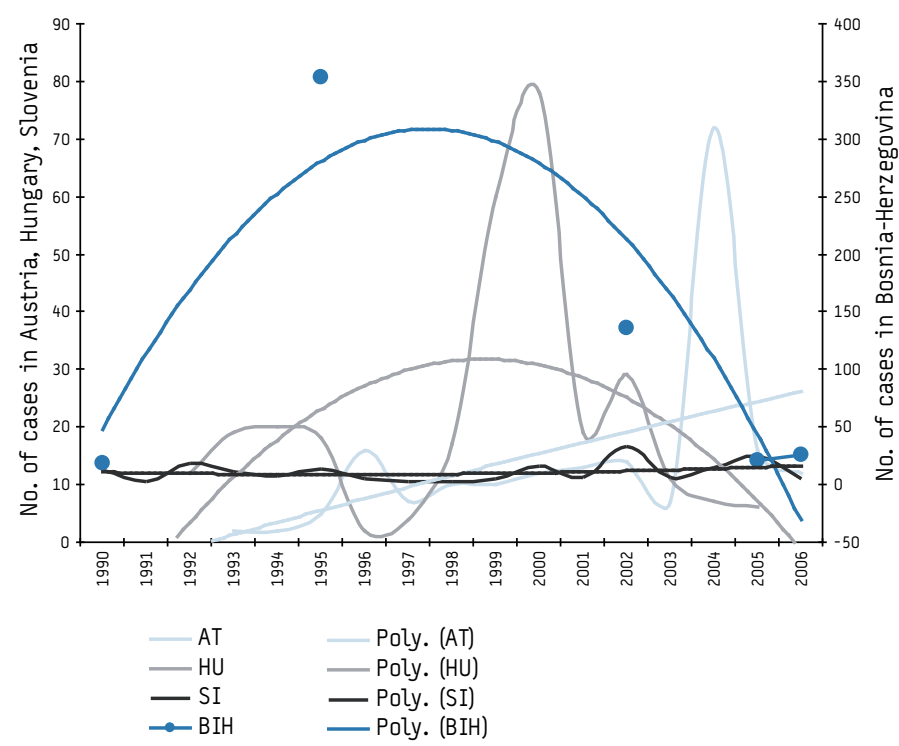

Dark blue: yearly number of cases in Bosnia-Herzegovina Light blue: yearly number of cases in Austria Dark grey: yearly number of cases in Slovenia Light grey: yearly number of cases in Hungary

Poly : Polynomial trendline: Calculates the least squares fit through points by using the following equation:

$y=b+c 1 x+c 2 \times 2+c 3 \times 3+\ldots . . c 6 \times 6$, where $b$ and $c 1 . . . c 6$ are constants.

Trendlines in corresponding colour. 
for $95 \%$ of the nation's cases: Between 1996 and 2006, 89,162 cases were detected, the vast majority due to PUUV infection. In the Asian part of the Russian Federation, far fewer cases were noted, with DOBV, SAAV, SEOV, Hantaan (HTNV) and Amur virus (AMRV) as the causal agents (A. Platonov, personal communication).

The number of human cases is on the rise in almost all European countries and record numbers were noted in Finland over the last five years (2,603 cases in 2002, 2,526 cases in 2005), Sweden (459 cases in 2004) and Belgium (372 cases in 2005) (Table 1). The total number of reported cases by country is summarised in Table 1. Mild winters and more frequent and more productive mast events allow more rodents to survive the winter Particularly mild winters are responsible for an early start of the breeding season and, in consequence, for larger rodent populations [6-8].

\section{Years with increased hantavirus infection activity}

Increased hantavirus activity in epidemic years is not synchronised geographically and chronologically in the participating countries (Table 2). Based on the available data, we present the trends.

\section{Belgium and France}

In both countries the disease followed a three-year epidemic cycle prior to 1999 (1990, 1993, 1996, 1999) [9,10]. Between 1999 and 2005, a two-year cycle was observed (1999, 2001, 2003, 2005). The year 2006 (163 cases) was again an epidemic year, and 2007 with 262 cases detected emerged as the third consecutive epidemic year. As France and Belgium are geographically located in the temperate deciduous broad leaf-tree biome, rodent cycles are regulated by masting, i.e. the available food from - mainly - oak and beech trigger higher rodent population densities and increased virus circulation in the population, represented by considerable higher antibody seroprevalences (Figure 4 and 5). The 2006 epidemic was probably due to extensive (B. Van der Aa, Instituut voor Natuur- en Bosonderzoek, manuscript in preparation) masting of oak and beech in the autumn of 2004; this mast probably provided sufficient food for rodents even in autumn and winter 2005. In autumn 2006, an

\section{F I G U R E 4}

Relation between human cases, oak mast and Puumala virus seroprevalence in rodents

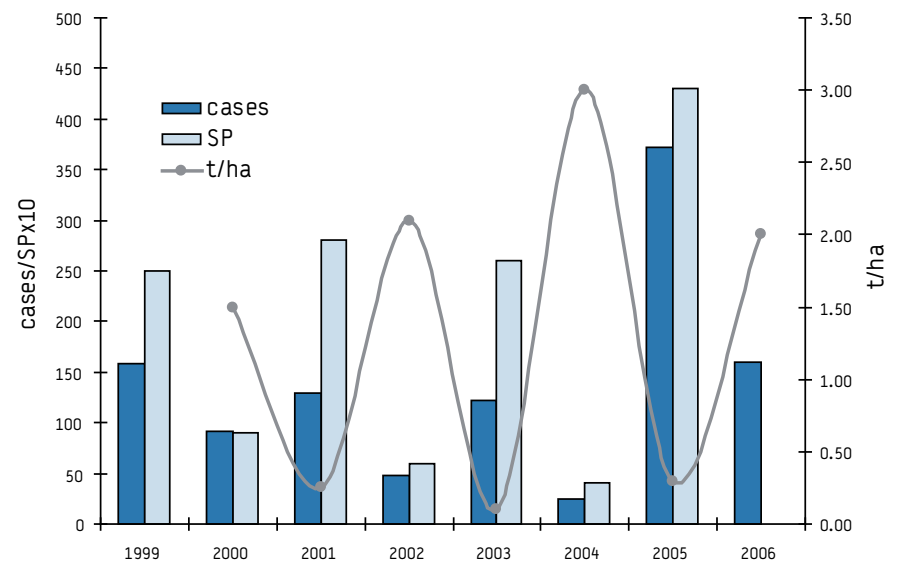

Cases: yearly numbers of cases 1999-2006 (dark blue bars)

SP: mean PUUV seroprevalence in rodents on ten sites in Belgium (light blue bars) $\mathrm{t} / \mathrm{ha}$ : tons of acorns per hectare (grey line). oak mast occurred again which was responsible for the increased hantavirus activity in 2007.

Adding a trend line to the dataset shows yet another remarkable feature; although both countries share a hyperendemic area, the trend for Belgium is increasing while the trend for France indicates a stabilisation of the situation. In 1985 the hantavirus activity in both countries was rather similar. The discrepancy between France and Belgium was marked in 2006: France (see: http:// www.invs.sante.fr/surveillance/fhsr/points.htm) had very few cases, while Belgium had an increased number of cases (http://www.iph. fgov.be/epidemio/epinl/plabnl/plabannl/06_053n_v.pdf). The key factor, however, is the pattern change in 1999, which is so far unexplained. Abiotic factors like climatic conditions probably play a role $[9,10]$

\section{Finland, Norway and Sweden}

With 1,084, 3,516 and 24,672 detected cases, respectively, Norway, Sweden and Finland account for most of the hantavirus cases in Europe. Located in the boreal forest biome, rodent population density cycles depend mainly on predator-prey mechanisms. Incidences of HFRS almost as high as in Finland occur in parts of European Russia (e.g. Bashkiria and Udmurtia regions) and parts of northern Sweden. However, the epidemiological pattern on the national scale in Finland seems to be changing [11]. The 3-4 year cycles were less synchronised before the late 1990s, but more recently the whole southern part of Finland seems to be in a single cycle. The increasing trend, in the number of human cases also in 'low activity' years, may be due to better diagnostics.

\section{Austria, Hungary, Slovenia, Bosnia-Herzegovina}

With 198, 302, 221 and 555 detected cases, respectively, these countries experience the co-circulation of two or three hantavirus serotypes, PUUV, DOBV, and SAAV. Austria represents an interesting mixture of patterns: in low altitudes the mast-year pattern prevails while at higher altitudes the cyclic pattern is seen (S. Aberle, personal communication). The number of cases in

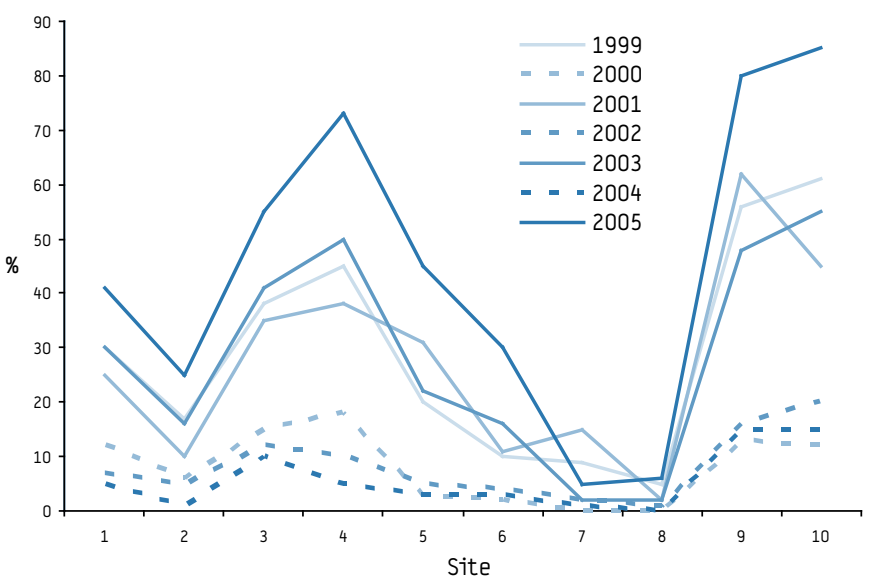

Dotted lines: seroprevalence in M. glareolus at 10 trapping sites in Belgium in non-epidemic years

Lines: seroprevalence in M. glareolus at 10 trapping sites in Belgium in epidemic years 
Bosnia-Herzegovina peaked significantly in 1995 (Table 2), during the conflict in that region.

\section{Local rodent species and circulating hantaviruses}

Although in most EU Member States and collaborating countries between 10 and 20 rodent species on average occur locally, only M. glareolus, $A$. sylvaticus, $A$. flavicollis, $A$. agrarius, $R$. norvegicus, Microtus agrestis, $M$. arvalis, Mus musculus and Mus spretus were reported as being present. The reported rodent species reflect those known or suspected of carrying a hantavirus serotype and other, non-suspect local rodent species were clearly not taken into account.

Puumala (PUUV), Tula (TULV), Dobrava, (DOBV), Saaremaa (SAAV) and Seoul (SEOV) hantaviruses were the serotypes reported as circulating both in humans and carrier rodents in the EU Member States and collaborating countries (Table 1).

\section{Pathogenic hantaviruses in the EU}

This survey confirmed that PUUV and DOBV have been causing the vast majority of human cases in the participating countries $[11,12]$, with the exception of Switzerland, where the only case was associated with TULV [13]. Recently, SAAV was also found to be responsible for human cases in eastern Europe [14]. No confirmed cases of SEOV infection have so far been reported in the EU Member States, though an unpublished case, confirmed by focus reduction neutralization tests (FRNT), occurred in France ( $\AA$. Lundkvist, personal communication, see also [3]).

Imported hantavirus cases have been rare and were caused by DOBV in Sweden and Austria, HTNV in Austria, and Sin Nombre virus (SNV) in France.

In western and northern Europe (Fennoscandia), only PUUV infections were reported $[11,12]$. Increasing from the west and north to the east in the EU, the PUUV/ DOBV infection ratio varied from $3.6 \%$ in southern Germany to more than $50 \%$ in Slovenia and up to $100 \%$ in Greece. Notably, in Germany, SAAV infections have also been designated as DOBV-Aa. In south-eastern Europe, the DOBV-Af. variant is predominant.

\section{Discussion}

Before 1990, hantavirus infections were probably heavily underdiagnosed, due to lack of reliable diagnostic tools. We assume that a reasonable coverage of hantavirus surveillance is achieved if the level of surveillance and awareness in a country enables its national public health system to sufficiently determine, whether the disease is endemic and to what extent public health is affected by its presence. As of 1990, this has been achieved also for those countries with a passive hantavirus surveillance system (testing performed in regional and/or reference laboratories, regular reporting to the national public health authorities). It has been estimated that only $10 \%$ of PUUV infections lead to disease [1]. Furthermore, it should be kept in mind that, given the unclear clinical picture and the benign clinical symptoms in a number of patients, some cases escape the surveillance systems.

In all three described biomes of Europe, the human HFRS epidemiology follows the local rodent cycle, meaning that human cases occur in the same rhythm as the rodent cycles. However, the epidemiological pattern and the epidemic cycles in central Europe are less clear than in western or northern Europe.

Active surveillance of carrier rodents and circulation of pathogenic hantaviruses is seldom or not at all maintained on a regular basis in most participating countries. Possible reasons for this might be that active surveillance involving fieldwork (rodent snap- and /or live-trapping, sampling and subsequent testing) is an expensive and time-consuming exercise with often no immediate result for the funding public health authorities. This kind of surveillance is mostly performed by research groups targeting the pathogen(s) and their transmission ecology, or initiated as a response to an epidemic, the latter being too late to have a positive and immediate impact on public health.

\section{Factors that determine the occurrence of hantavirus disease}

Of the hosts of pathogenic hantaviruses in Europe, the bank vole, the carrier of PUUV, has a distribution range that includes most of Europe. Still, human disease incidence and epidemiological patterns vary greatly across the continent. The yellow-necked mouse has not quite as wide a range as the bank vole and DOBV has not been found in the western and northern parts of Europe. As far as we know, SAAV occurs in most areas where its host, the striped field mouse, is found in central and eastern Europe [15].

Multiple factors influence the occurrence of the disease in a region. The geographical location and the habitat composition is important and in Europe three major biomes occur (Figure 6):

- the boreal forest;

- the temperate deciduous broad-leafed forest;

- and the Mediterranean scrub zone [14].

The boreal forest in northern Europe can be defined as a large homogenous landscape with relatively low biodiversity, true cyclic rodent population dynamics with an extended peak phase of more than a year, and its rodent population is usually considered to

F I G U R E 6

Terrestrial biomes in Europe

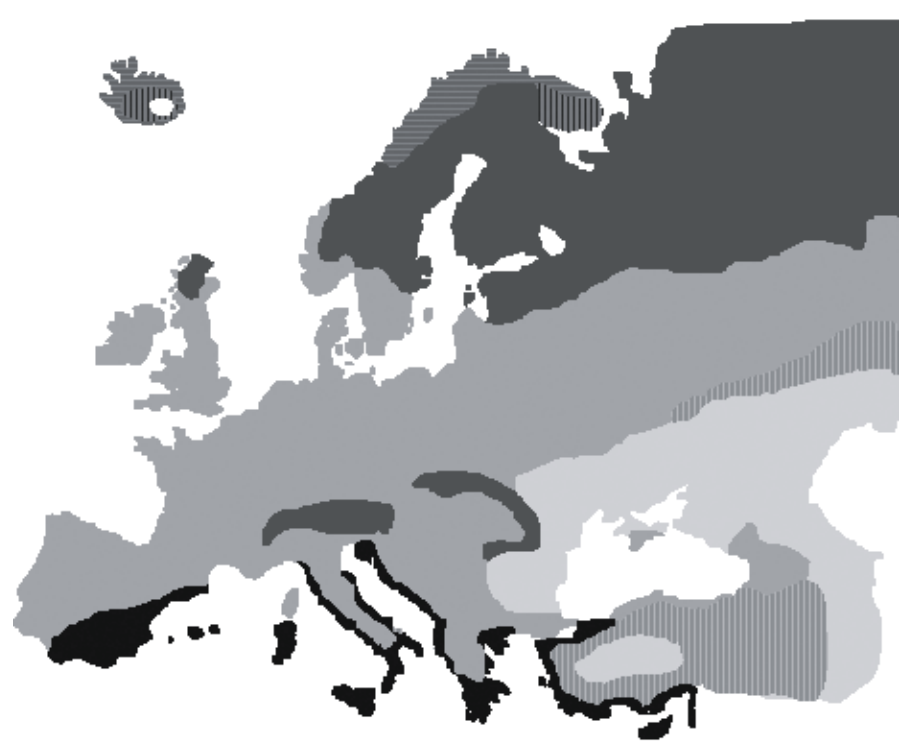

Mediterranean scrub Temperate deciduous forest Temperate boreal forest Moist steppe / Dry steppe 
be regulated by predator-prey interactions [16]. In contrast, in the mid-European temperate deciduous broad-leafed forest zone, more stable and seasonal rodent population dynamics occur, with principally mast-driven peaks. Mast years are years in which trees (mainly oak and beech) produce more seeds than usually. The normal seasonal peak densities in autumn are of short duration, while after a mast event, increased winter survival results in extended high-density periods in the following year, coinciding with HFRS outbreaks (see Figure 4). Due to intensive agriculture and land use for building, the landscapes are highly fragmented and heterogeneous. The important trees for masting are oaks (Quercus robur and $Q$. petracaea) and beech (Fagus sylvatica). The more biomass these species produce, the more significant is the mast effect on rodent populations $[17,18]$. The less efficient spread of rodents and virus in the temperate deciduous biome is reflected in the ten-fold lower number of human cases when compared to Fennoscandia (the boreal forest biome) (see Table 2).

The Mediterranean scrub integrates well-developed and diversified herbaceous, shrub and arboreal strata that often are dense to almost impenetrable. Rodent population dynamics likely respond to food availability, which in turn is dependent on rainfall [19].

Human behaviour probably plays a crucial role in the likelihood of human hantavirus infections. In a long-term seroprevalence study in rodents at multiple locations in Belgium, both inside and outside the epidemic area for human cases, the presence of PUUV was detected in all examined bank vole populations [12]. Data on the incidence of human hantavirus disease, however, did not correlate with these findings; i.e. in some regions with a high seroprevalence in rodents, only a few or no human cases occurred at the same time and vice versa. Instead, the incidence correlated with the socioeconomic status of the inhabitants of a region [20]. The PUUV incidence rate was higher in areas with a high proportion of broad-leaved forests and a low level of urbanisation. A high level of urbanisation thus limits PUUV transmission, while income correlated negatively with the disease incidence.

Hantaviruses are unexpectedly stable over more than 10 days at room temperature and probably remain infectious for many months during winter in northern Europe [21]. The change of climatic conditions could have a significant impact on the magnitude and amplitude of the occurrence of hantavirus infections. Although it is still too early to draw firm conclusions, this effect has already been observed in Europe $[9,16]$. In France and Belgium a threeyear epidemic cycle became a bi-annual cycle, and in Belgium, 2005, 2006 and 2007 can be considered three consecutive epidemic years (Table 2) [9]. In Finland, changes in the geographic synchronicity of rodent cycles have affected the incidence pattern at national level, although locally, human epidemiology follows the three-year vole cycles [16]. These spatial changes in the geography of rodent cycles have also occurred in Finland in the past. It may therefore be too early to draw conclusions regarding the effect of climate change.

\section{Public health impact of hantavirus infections}

DOBV infections, although relatively uncommon, cause severe HFRS with high case-fatality rate (CFR) around 10\% [22]. Due to the varying severity of PUUV infections, only $5-10 \%$ of infected humans experience clinical problems severe enough to seek medical help [1]. Although the CFR due to PUUV infections is very low ( $0.1 \%$ in Belgium and Finland) [1], about $5 \%$ of hospitalised
PUUV-HFRS patients require dialysis treatment. A severe clinical course of PUUV-HFRS is strongly associated with HLA-B8 and mild with HLA-B27 haplotype. Fatal cases have been due to fluid imbalance after shock, haemorrhages and necrosis in the pituitary gland, and encephalitis. In a five year follow-up of hospitalized PUUV-HFRS patients, increased blood pressure, cardiac pulse and proteinuria were observed as long-term consequences in $20 \%$ of the cases [23]. After 10 years of follow-up the effect had largely, but not totally, disappeared.

\section{Conclusions}

We conclude that hantavirus infections are widespread in Europe and that they have clear effects on public health. Unfortunately, as documented by the present ENIVD survey hantavirus infections are currently underestimated or not recognised by the medical and public health authorities in many countries, largely because diagnostics are not available.

\section{Acknowledgements}

The authors report on behalf of the participating members of the European Network for diagnostics of Imported Viral Diseases (ENIVD). The full list of ENIVD members is available on http://www.enivd.de. This project has been partially funded under the EU 6th Framework Programme (GOCE-CT-2003-010284 EDEN) and is officially catalogued by the EDEN Steering Committee as EDEN0074 and under the ENIVD contract number 2004206.

The authors thank Professor Heikki Henttonen, Finnish Forest Research Institute, Vantaa Research Unit, Vantaa, Finland for his valuable comments and advice.

\section{References}

1. Vapalahti 0 , Mustonen J, Lundkvist A, Henttonen H, Plyusnin A, Vaheri A..Hantavirus infections in Europe. Lancet Infect Dis. 2003;3(10):653-61.

2. Kallio-Kokko H, Uzcategui N, Vapalahti O, Vaheri A. Viral Zoonoses in Europe. FEMS Microbiol Rev. 2005;29(5):1051-77.

3. Heyman P, Plyusnina A, Berny P, Cochez C, Artois M, Zizi M, et al Seoul hantavirus in Europe: first demonstration of the virus genome in wild Rattus norvegicus captured in France. Eur J Clin Microbiol Infect Dis. 2004;23(9):711-7.

4. Kim YS, Ahn C, Han JS, Kim S, Lee JS, Lee PW. Hemorrhagic fever with renal syndrome caused by the Seoul virus. Nephron. 1995;71(4):419-27.

5. LeDuc JW, Childs JE, Glass GE. The Hantaviruses, etiologic agents of hemorrhagic fever with renal syndrome: a possible cause of hypertension and chronic renal disease in the United States. Annu Rev Public Health. 1992;13:79-98

6. Lambin X, Bretagnolle $V$, Yoccoz NG. Vole population cycles in northern and southern Europe: is there a need for different explanations for single pattern? J Anim Ecol. 2006;75(2):340-9.

7. Hansen TF, Stenseth NC, Henttonen $H$, Tast J. Intespecific and intraspecific competition as causes of direct and delayed dencity dependence in a fluctuating vole population. Proc Natl Acad Sci U S A. 1999 Feb 2;96(3):986-91.

8. Ergon T, Lambin X, Stenseth NC. Life-history traits of voles in a fluctuating population respond to the immediate environment. Nature. 2001;411(6841):1043-5.

9. Heyman P. Puumala virus infections - Belgium. ProMED-mail. 1 June 2007 Archive no. 20070601.1777. Available from: http://www.promedmail.org/pls/ otn/f?p= 2400:1202:1963399673306051::NO::F2400_P1202_CHECK_DISPLAY,F2400_ P1202_PUB_MAIL_ID:X,37667

10. Heyman P, Vervoort T, Escutenaire S, Degrave E, Konings J, Vandenvelde C, et al. Incidence of hantavirus infections in Belgium. Virus Res. 2001;77(1):71-80.

11. Brummer-Korvenkontio M, Vapalahti $O$, Henttonen $H$, Koskela $P$, Kuusisto $P$, Vaheri A. Epidemiological study of nephropathia epidemica in Finland 1989-96. Scand J Infect Dis. 1999;31(5):427-35.

12. Heyman P, Van Mele R, De Jaegere F, Klingström J, Vandenvelde C, Lundkvist A, et al. Distribution of hantavirus foci in Belgium. Acta Trop. 2002;84(3):183-8 
13. Schultze D, Lundkvist A, Blauenstein U, Heyman P. Tula virus infection associated with fever and exanthema after a wild rodent bite. Eur J Clin Microbiol Infect Dis. 2002;21(4):304-6.

14. Plyusnin A, Vaheri A, Lundkvist A. Saaremaa Hantavirus Should Not Be Confused with Its Dangerous Relative, Dobrava Virus. J Clin Microbiol. 2006;44(4):1608-9.

15. Mitchell-Jones AJ, Amori G, Bogdanowicz W, Krystufek B, Reijnders PJH, F. Spitzenberger, et al. The Atlas of European Mammals. London: T\&AD Poyser Ltd; 1999.

16. Henttonen, H. and Vaheri, A. Hemorrhagic fever with renal syndrome - Finland - Update. ProMED-mail. 23 April 2006. Archive no. 20060423.1184. Available from: http://www.promedmail.org/pls/otn/f?p= 2400:1202:1448496073068887::N 0::F2400_P1202_CHECK_DISPLAY,F2400_P1202_PUB_MAIL_ID:X,32745

17. Suchomel, J. 2007. Contribution to the knowledge of Clethrionomys glareolus populations in forest of managed landscape in Southern Moravia (Czech Republic). J. For. Sci. 2007;53(7):340-4

18. Wereszczyńska AM, Nowakowski WK, Nowakowski JK, Jędrzejewska B. Is food quality responsible for the cold-season decline in bank vole density? Laboratory experiment with herb and acorn diets. Folia Zool. 2007;56(1):23-32.

19. Corominas IT. Distribution, population dynamics and habitat selection of small mammals in Mediterranean environments: the role of climate, vegetation structure and predation risk [dissertation].Univ of Barcelona; 2004.

20. Linard C, Lamarque P, Heyman P, Ducoffre G, Luyasu V, Tersago K, Determinants of the geographic distribution of Puumala hantavirus and Lyme borreliosis infections in Belgium. Int J Health Geogr. 2007;6:15.

21. Kallio ER, Klingström J, Gustafsson E, Manni T, Vaheri A, Henttonen H, et al. Prolonged survival of Puumala hantavirus outside the host: evidence for indirect transmission via the environment. J Gen Virol. 2006;87(Pt 8):2127-34.

22. Avsic-Zupanc T, Petrovec M, Furlan P, Kaps R, Elgh F, Lundkvist A. Hemorrhagic fever with renal syndrome in the Dolenjska region of Slovenia--a 10-year survey. Clin Infect Dis. 1999;28(4):860-5.

23. Vapalahti K, Paunio M, Brummer-Korvenkontio M, Vaheri A, Vapalahti 0. Puumala virus infections in Finland: increased occupational risk for farmers. Am J Epidemiol. 1999;149(12):1142-51.

This article was published on 10 July 2008

Citation style for this article: Heyman P, Vaheri A, the ENIVD members. Situation of hantavirus infections and haemorrhagic fever with renal syndrome in European countries as of December 2006. Euro Surveill. 2008;13(28):pii=18925. Available online: http://www.eurosurveillance.org/ViewArticle.aspx?ArticleId=18925 